\title{
Sensorless Control Of Dual-Three Phase PMSM Based Aircraft Electric Starter/Generator System Using Model Reference Adaptive System Method
}

\author{
Linhui Fan, Tao Yang, Mohamed Rashed, Serhiy Bozhko \\ Department of Electrical and Electronics Engineering, University of Nottingham, Nottingham, UK \\ Email: Tao.Yang@nottingham.ac.uk
}

\begin{abstract}
This paper presents a sensorless control technique based on Model Reference Adaptive System (MRAS) for a symmetric dual three-phase permanent magnet synchronous machine (DTP-PMSM) whose sets of windings are spatially shifted by 60 degrees. The control design of starter/generator $(\mathrm{S} / \mathrm{G})$ system is studied. The analytical controller design is presented. The effectiveness of the controller is demonstrated from time-domain simulations.
\end{abstract}

Keywords-Dual Three-Phase PMSM, MRAS, startergenerator, sensorless control.

\section{INTRODUCTION}

Global tendency towards environmentally responsible air transportation results in significant changes to many aircraft systems technologies. The state-of-the art on-board systems are expected to be more efficient, safer, simpler in servicing and easier in maintenance $[1,2]$. As a result, many existing hydraulic and pneumatic power-driven systems are being replaced by their electrical counterparts. This trend is known as a move towards the "more electric aircraft" (MEA). In recent years, multi-phase machine has been widely used in various applications such as MEA [3]. In the last two decades, a growing interest in multi-phase machines has risen due to the fact that these machines can provide notable improvements in various aspects of performance when compared with the use of their conventional three-phase counterparts [4]. The potential advantages of multiphase machines include: reduced phase current rating and torque ripple; less DC link harmonic current; smooth magneto motive force (MMF); improved efficiency [5]; excellent fault tolerant characteristics and higher reliability at system level [4-7]. In addition, reliability is greatly improved since the machine can operate continuously even if one or several phases (in some cases) are lost [3]. One of the most attractive multi-phase machines is the six-phase or dual three-phase (DTP) machine as depicted in Fig. 1. A DTP winding machine has two identical star-connected three-phase stator windings which have isolated neutral points [8]. Considering the spatially shifted angle between two sets of three-phase windings, DTP machines can be classified as symmetrical (shifted by 60 electrical degrees) machines and asymmetric (shifted by 30 electrical degrees) machines. According to [9], symmetric DTP-PMSM is preferred to satisfy the severe fault-tolerant requirements imposed by the specific aerospace application. Hence, a symmetric DTP-PMSM is investigated in this study to develop a mechatronic device for turboprop aircraft applications.

Since the space in the gear box is quite limited and not large enough to install mechanical speed/position sensors, sensorless control is considered. One additional benefit brought by the sensorless control strategy is the improved system reliability since it reduces the vulnerable components (mechanical sensor) in entire system. Usually, sensorless control can be classified into two major groups [10]. One is based on mathematical models of machine such as the model reference adaptive system (MRAS) $[11,12]$ and the other one is based on the rotor saliency such as high frequency signal injection techniques $[13,14]$. It has been found that sensorless control design for an aircraft electric $\mathrm{S} / \mathrm{G}$ system based on multiphase machines especially for symmetric DTP-PMSM has not been studied in enough details, hence the paper addresses this gap. In this study, MRAS is developed to estimate rotor speed and position since it presents immediate advantage that the models are simple, easy to implement and have direct physical interpretation.

The paper is organized as follows: DTP-PMSM model is reviewed in section II; control design of $\mathrm{S} / \mathrm{G}$ system is illustrated in section III and MRAS estimation method is presented in section IV; simulations results are included in section $\mathrm{V}$, while conclusions are provided in the last section.

\section{Dual Three-Phase PMSM Model}

In this section, mathematic models of DTP-PMSM in both three-phase coordinate system and $d q$ rotating frame are developed.

\section{A. Mathematical Model in Three-Phase Coordinate System}

The voltage and flux equations in three phase coordinate system of a DTP-PMSM can be written as

$$
\begin{gathered}
\boldsymbol{u}_{s}=R \boldsymbol{i}_{s}+\frac{d \varphi_{s}}{d t} \\
\boldsymbol{\varphi}_{s}=\boldsymbol{L}_{s} \boldsymbol{i}_{\boldsymbol{s}}+\lambda \varphi_{m}
\end{gathered}
$$

where

$$
\begin{aligned}
& \boldsymbol{u}_{\boldsymbol{s}}=\left[\begin{array}{llllll}
u_{A} & u_{A} & u_{C} & u_{U} & u_{V} & u_{W}
\end{array}\right]^{T} \text { is stator voltage; } \\
& \boldsymbol{i}_{\boldsymbol{s}}=\left[\begin{array}{llllll}
i_{A} & i_{B} & i_{C} & i_{U} & i_{V} & i_{W}{ }^{T} \text { is stator current; }
\end{array}\right. \\
& \boldsymbol{\varphi}_{s}=\left[\begin{array}{llllll}
\varphi_{A} & \varphi_{B} & \varphi_{C} & \varphi_{U} & \varphi_{V} & \varphi_{W}
\end{array}\right]^{T} \text { is stator flux; }
\end{aligned}
$$

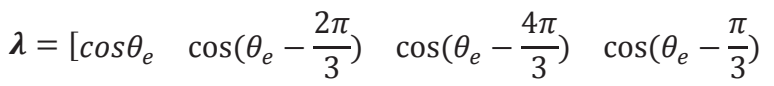

$$
\begin{aligned}
& \left.\cos \left(\theta_{e}-\pi\right) \quad \cos \left(\theta_{e}-\frac{5 \pi}{3}\right)\right]^{T} \text { is flux coefficient matrix; }
\end{aligned}
$$

$\theta_{e}$ is the electrical rotor position in radians;

$R$ is stator resistance; 


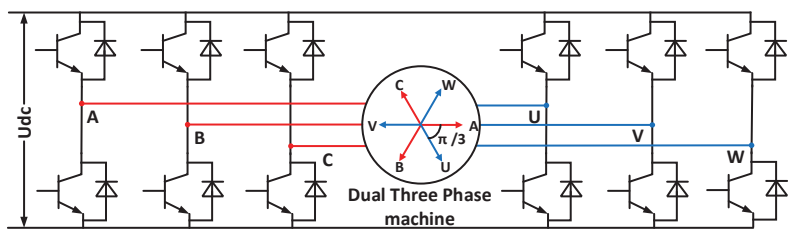

Fig. 1 DTP-PMSM drive system [15]

$\varphi_{m}$ is permanent magnet flux;

$\boldsymbol{L}_{\boldsymbol{s}}$ is the inductance coefficient matrix which can be presented as

$$
\boldsymbol{L}_{\boldsymbol{s}}=L_{z} \boldsymbol{I}+\left(\frac{L_{d}+L_{q}-2 L_{z}}{3}\right) \boldsymbol{M}_{\boldsymbol{o}}+\left(\frac{L_{d}-L_{q}}{3}\right) \boldsymbol{M}_{\boldsymbol{x}}
$$

where $L_{z}$ is stator leakage inductance, $L_{d}$ and $L_{q}$ are stator inductances in $d$-axis and $q$-axis respectively. $I$ is a unity matrix with six columns and six rows. $\boldsymbol{M}_{\boldsymbol{o}}$ and $\boldsymbol{M}_{\boldsymbol{x}}$ are detailed in Appendix A. The system parameters used in this study are given in Appendix B.

The electromagnetic torque of the PMSM is obtained by taking the partial derivative of the system co-energy with respect to rotor position angle [16].

$$
T_{e}=P_{P} \frac{\partial}{\partial \theta_{e}}\left(\frac{1}{2} i_{s}{ }^{T} \boldsymbol{L}_{\boldsymbol{s}} \boldsymbol{i}_{\boldsymbol{s}}+\boldsymbol{i}_{\boldsymbol{s}}{ }^{T} \lambda \varphi_{m}\right)
$$

where $P_{P}$ is the number of pole pairs.

\section{B. Model Representation in dq Rotating Frame}

By ignoring zero sequence component, DTP-PMSM can be represented as two single three-phase machines with mutual coupling through transformation matrix $T_{s}[4,17]$,

$$
\left[\begin{array}{llll}
f_{d 1} & f_{q 1} & f_{d 2} & f_{q 2}
\end{array}\right]^{T}=T_{s}\left[\begin{array}{llllll}
f_{A} & f_{B} & f_{C} & f_{U} & f_{V} & f_{W}
\end{array}\right]^{T}
$$

$f$ stands for variable such as voltage, current and flux (5)

$$
\begin{gathered}
T_{s}=\left[\begin{array}{cc}
T_{1} & 0 \\
0 & T_{2}
\end{array}\right] \\
T_{1}=\frac{2}{3}\left[\begin{array}{ccc}
\cos \theta & \cos \left(\theta-\frac{2 \pi}{3}\right) & \cos \left(\theta+\frac{2 \pi}{3}\right) \\
-\sin \theta & -\sin \left(\theta-\frac{2 \pi}{3}\right) & -\sin \left(\theta+\frac{2 \pi}{3}\right)
\end{array}\right] \\
T_{2}=\frac{2}{3}\left[\begin{array}{ccc}
\cos \left(\theta-\frac{\pi}{3}\right) & \cos (\theta-\pi) & \cos \left(\theta+\frac{\pi}{3}\right) \\
-\sin \left(\theta-\frac{\pi}{3}\right) & -\sin (\theta-\pi) & -\sin \left(\theta+\frac{\pi}{3}\right)
\end{array}\right]
\end{gathered}
$$

where $\theta$ is rotor position in electrical angle.

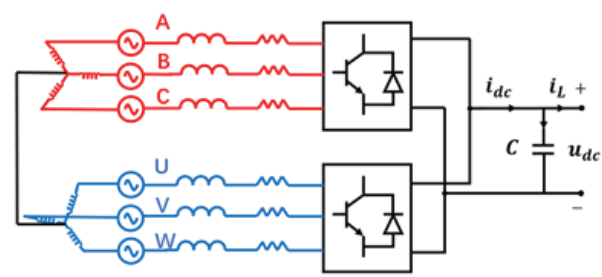

Fig. 2 Block diagram of load current and voltage.
The voltage and flux equations for DTP-PMSM in $d q$ frame can be deduced as (9) and (10) by substituting (5)-(8) into (1) and (2):

$$
\begin{aligned}
& {\left[\begin{array}{l}
u_{d 1} \\
u_{q 1} \\
u_{d 2} \\
u_{q 2}
\end{array}\right]=R\left[\begin{array}{l}
i_{d 1} \\
i_{q 1} \\
i_{d 2} \\
i_{q 2}
\end{array}\right]+\left[\begin{array}{l}
\dot{\varphi}_{d 1} \\
\dot{\varphi}_{q 1} \\
\dot{\varphi}_{d 2} \\
\dot{\varphi}_{q 2}
\end{array}\right]+\omega_{e}\left[\begin{array}{cccc}
0 & -1 & 0 & 0 \\
1 & 0 & 0 & 0 \\
0 & 0 & 0 & -1 \\
0 & 0 & 1 & 0
\end{array}\right]\left[\begin{array}{c}
\varphi_{d 1} \\
\varphi_{q 1} \\
\varphi_{d 2} \\
\varphi_{q 2}
\end{array}\right]} \\
& {\left[\begin{array}{l}
\varphi_{d 1} \\
\varphi_{q 1} \\
\varphi_{d 2} \\
\varphi_{q 2}
\end{array}\right]=\left[\begin{array}{cccc}
L_{d} & 0 & L_{d d} & 0 \\
0 & L_{q} & 0 & L_{q q} \\
L_{d d} & 0 & L_{d} & 0 \\
0 & L_{q q} & 0 & L_{q}
\end{array}\right]\left[\begin{array}{l}
i_{d 1} \\
i_{q 1} \\
i_{d 2} \\
i_{q 2}
\end{array}\right]+\left[\begin{array}{l}
1 \\
0 \\
1 \\
0
\end{array}\right] \varphi_{m}(1}
\end{aligned}
$$

where $L_{d}$ and $L_{q}$ are total inductances in $d q$ frame; $L_{d d}$ and $L_{q q}$ are coupling inductances between two sets of windings which have the following relationships:

$$
\begin{aligned}
& L_{d}=L_{d d}+L_{z} \\
& L_{q}=L_{q q}+L_{z}
\end{aligned}
$$

Substitute (10) into (9), giving

$$
\begin{gathered}
{\left[\begin{array}{l}
u_{d 1} \\
u_{q 1} \\
u_{d 2} \\
u_{q 2}
\end{array}\right]=\left[\begin{array}{cccc}
R & -\omega_{e} L_{q} & 0 & -\omega_{e} L_{q q} \\
\omega_{e} L_{d} & R & \omega_{e} L_{d d} & 0 \\
0 & -\omega_{e} L_{q q} & R & -\omega_{e} L_{q} \\
\omega_{e} L_{d d} & 0 & \omega_{e} L_{d} & R
\end{array}\right]\left[\begin{array}{l}
i_{d 1} \\
i_{q 1} \\
i_{d 2} \\
i_{q 2}
\end{array}\right]+} \\
{\left[\begin{array}{cccc}
L_{d} & 0 & L_{d d} & 0 \\
0 & L_{q} & 0 & L_{q q} \\
L_{d d} & 0 & L_{d} & 0 \\
0 & L_{q q} & 0 & L_{q}
\end{array}\right]\left[\begin{array}{c}
\dot{i}_{d 1} \\
\dot{i}_{q 1} \\
\dot{i}_{d 2} \\
\dot{i}_{q 2}
\end{array}\right]+\omega_{e}\left[\begin{array}{c}
0 \\
\varphi_{m} \\
0 \\
\varphi_{m}
\end{array}\right]}
\end{gathered}
$$

One can obtain the following torque equation by transforming (4) into the $d q$ rotating frame using (5)-(8):

$T_{e}=\frac{3}{2} P_{P}\left[\left(L_{d}-L_{q}\right)\left(i_{d 1}+i_{d 2}\right)\left(i_{q 1}+i_{q 2}\right)+\left(i_{q 1}+i_{q 2}\right) \varphi_{m}\right]$

In starter mode, the controlled variable is machine speed which is governed by the following equation [18]:

$$
J \frac{d \omega_{m}}{d t}=T_{e}-T_{L}
$$

where $T_{L}$ is engine torque during start-up, $J$ is a total inertia and $\omega_{m}$ is mechanical speed.

In generator mode, the controlled variable, according to the designed system requirements, is output DC current. This can be governed by the converter equation as follows [18]:

$$
i_{d c}=\frac{3}{4}\left(m_{d 1} i_{d 1}+m_{q 1} i_{q 1}+m_{d 2} i_{d 2}+m_{q 2} i_{q 2}\right)
$$

where $m_{d}$ and $m_{q}$ are the modulation indexes of the converter [18]:

$m_{d 1}=\frac{2 u_{d 1}}{u_{d c}}, m_{q 1}=\frac{2 u_{q 1}}{u_{d c}}, m_{d 2}=\frac{2 u_{d 2}}{u_{d c}}, m_{q 2}=\frac{2 u_{q 2}}{u_{d c}}$ 


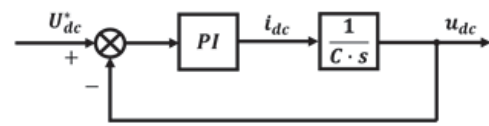

Fig. 3 Block diagram of DC voltage control loop.

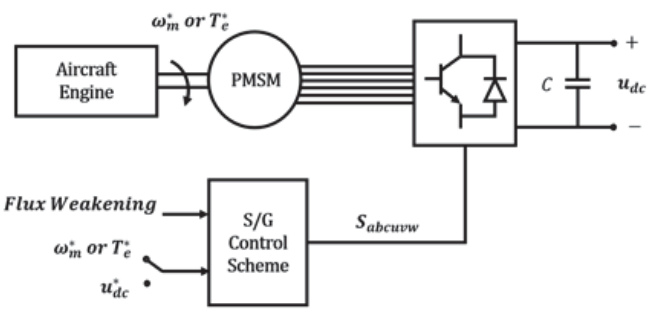

Fig. 4 Conceptual control scheme of S/G system.

$u_{d c}$ is the converter output voltage (across the output capacitor $C$ ) [18]. As illustrated in Fig. $2, u_{d c}$ and $i_{d c}$ has following relationship:

$$
C \frac{d u_{d c}}{d t}=i_{d c}-i_{L}
$$

where $i_{L}$ is the current drawn by the load [19].

Assuming $i_{L}$ is neglected, (18) can be simplified as:

$$
u_{d c}=\frac{i_{d c}}{C \cdot s}
$$

where $s$ is deferential operator. According to (19), a PI controller is designed to control $u_{d c}$, which is shown in Fig. 3.

According to energy conservation law, the electrical power generated by the system is equal to the mechanical power injected into the system. Hence, electromagnetic torque can be presented as

$$
T_{e}=\frac{u_{d c} i_{d c}}{\omega_{m}}
$$

Since electromagnetic torque is proportional to $q$-axis current, combining (19) and (20), the reference of $q$-axis current can be generated by $u_{d c}$, as illustrated in Fig. 9 .

\section{CONTROL DeSIGN}

In this section, design of control system is investigated. Firstly, capabilities and limitations of S/G system are analysed. According to the capabilities and limitations of S/G system, a direct current flux weakening control approach is developed to avoid overmodulation. Control of starter mode and generator mode are mentioned at the end of this section.

The general control scheme for the $\mathrm{S} / \mathrm{G}$ can be seen in Fig. 4. $\omega_{m}$ is the mechanical speed, $S_{a b c u v w}$ is six phase switching states and all variables with the $*$ notation denote the reference value of controlled variable.

\section{A. S/G System Capabilities and Limitations.}

Control of the system is established in terms of a synchronously rotating $d q$ frame which is aligned with the rotor. Current control has been solved in a traditional method by employing a proportional plus integral current controller

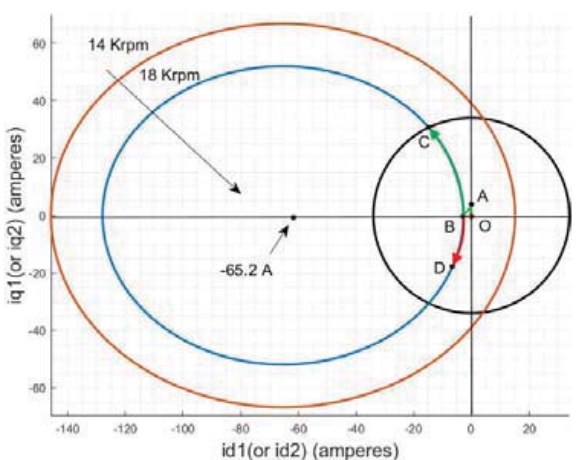

Fig. 5 ACHIEVE system voltage and current limit circles.

with standard tuning [21] The closed-loop natural frequency is set to $500 \mathrm{~Hz}$ with a damping factor of 0.707 . The parameters of the system are detailed in Appendix B.

There are two factors that restrict the control performance in the designed system. One is the maximum current of the converter IGBTs $I_{\max }=34 \mathrm{~A}$ and the other is the machine maximum phase voltage on the converter ac side $U_{\max }=$ $\frac{540}{\sqrt{3}} V=311 \mathrm{~V}$. Thus, the following relationships exist:

$$
U_{\max }{ }^{2} \geq u_{d_{1,2}}{ }^{2}+u_{q_{1,2}}{ }^{2}
$$

Assuming steady state operation and ignoring stator resistance, the machine electrical equations (13) can be reduced to:

$$
\begin{aligned}
& {\left[\begin{array}{l}
u_{d 1} \\
u_{q 1} \\
u_{d 2} \\
u_{q 2}
\end{array}\right]=\left[\begin{array}{cccc}
0 & -\omega_{e} L_{q} & 0 & -\omega_{e} L_{q q} \\
\omega_{e} L_{d} & 0 & \omega_{e} L_{d d} & 0 \\
0 & -\omega_{e} L_{q q} & 0 & -\omega_{e} L_{q} \\
\omega_{e} L_{d d} & 0 & \omega_{e} L_{d} & 0
\end{array}\right]\left[\begin{array}{l}
i_{d 1} \\
i_{q 1} \\
i_{d 2} \\
i_{q 2}
\end{array}\right]+} \\
& \omega_{e}\left[\begin{array}{c}
0 \\
\varphi_{m} \\
0 \\
\varphi_{m}
\end{array}\right]
\end{aligned}
$$

Since the two sets of three-phase windings are exactly symmetric, if the current controllers of these two $d q$ frames share same parameters, (22) can be expressed as:

$$
\begin{gathered}
{\left[\begin{array}{l}
u_{d 1} \\
u_{q 1} \\
u_{d 2} \\
u_{q 2}
\end{array}\right]=\left[\begin{array}{cccc}
0 & -\omega_{e} L_{Q} & 0 & 0 \\
\omega_{e} L_{D} & 0 & 0 & 0 \\
0 & 0 & 0 & -\omega_{e} L_{Q} \\
0 & 0 & \omega_{e} L_{D} & 0
\end{array}\right]\left[\begin{array}{l}
i_{d 1} \\
i_{q 1} \\
i_{d 2} \\
i_{q 2}
\end{array}\right]+} \\
\omega_{e}\left[\begin{array}{c}
0 \\
\varphi_{m} \\
0 \\
\varphi_{m}
\end{array}\right]
\end{gathered}
$$

where

$$
\begin{aligned}
& L_{D}=L_{d}+L_{d d} \\
& L_{Q}=L_{q}+L_{q q}
\end{aligned}
$$

From (23), the following can be derived: 


$$
\begin{gathered}
u_{d_{1,2}}=-\omega_{e} L_{Q} i_{q_{1,2}} \\
u_{q_{1,2}}=\omega_{e}\left(L_{D} i_{d_{1,2}}+\varphi_{m}\right)
\end{gathered}
$$

The voltage limit equation can be deduced using (21), (26) and (27) [22]:

$$
\left(\frac{U_{\max }}{\omega_{e} L_{Q}}\right)^{2}=\left(\frac{L_{D}}{L_{Q}} i_{d_{1,2}}+\frac{\varphi_{m}}{L_{Q}}\right)^{2}+i_{q_{1,2}}{ }^{2}
$$

The following equation represents current limit in terms of $d q$ frame currents [22]:

$$
I_{\max }{ }^{2} \geq i_{d_{1,2}}{ }^{2}+i_{q_{1,2}}{ }^{2}
$$

The voltage and current limit circles can be plotted according to (28) and (29) on an $i_{d}-i_{q}$ plane. The radius of the voltage ellipse decreases as the speed increases from 14 $\mathrm{krpm}$ to $18 \mathrm{krpm}$, as shown in Fig. 5. The black circle represents the current limit while the others are the voltage limits at different operating speeds. Theoretically, infinite speed can be achieved as the center point is within the current limit circle. The center point of this circle is the critical current at $-\frac{\varphi_{m}}{L_{D}}$ or $-65.2 \mathrm{~A}$.

\section{B. Flux Weakening Control}

To avoid converter overmodulation, flux weakening control is introduced. In this study, flux weakening mode is achieved by controlling the $i_{d}$ current component (direct current method). Rigorous design of direct current method in both starter mode and generator mode has been investigated in [28]. As illustrated in Fig. 6, the machine voltage is controlled to $U_{\max }$ by voltage controller that produces the reference for $d$-axis current. And a dynamic limiter is used to limit reference of $q$-axis current $i_{q_{1,2}}{ }^{*}$. When $i_{q_{1,2}}{ }^{*}$ is within $\left[-i_{\text {qlim }},+i_{\text {qlim }}\right]$, where $i_{\text {qlim }}=\sqrt{I_{\text {max }}{ }^{2}-i_{d_{1,2}}^{*}}, i_{q_{1,2}}{ }^{*}$ is determined by the output of the speed controller, otherwise the dynamic limiter is active and it will be completely determined by $i_{d_{1,2}}{ }^{*}$ as shown in the following:

$$
i_{q_{1,2}}{ }^{*} \leq i_{q l i m}=\sqrt{I_{\max }^{2}-i_{d_{1,2}}^{*}}
$$

\section{Starter Mode Control}

In starter mode, the system task is to accelerate the engine to up to $18 \mathrm{krpm}$ which can be implemented by building a speed control system that facilitates smooth engine acceleration. The standard PI speed controller design procedure [21] is applied. The speed loop bandwidth is set to $5 \mathrm{~Hz}$ with a damping factor of 0.707 .

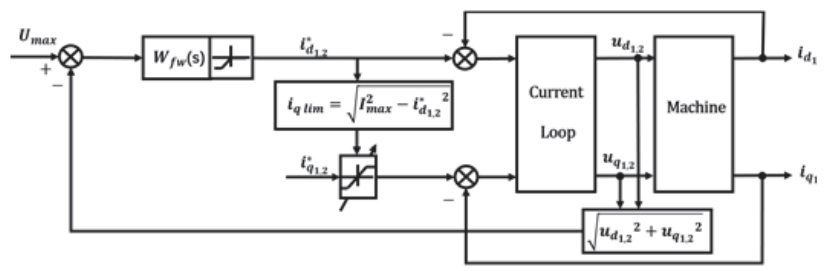

Fig. 6 Flux weakening control diagram.

\section{Generator Mode Control}

In generator mode, the speed of the engine is controlled externally, and control of the DC link bus power is the primary objective. The $\mathrm{S} / \mathrm{G}$ is designed to provide up to 20 $\mathrm{kW}$ of electrical power to the $540 \mathrm{~V}$ DC bus and should also be capable of operation in parallel with other power sources connected to the common DC bus. The control of DC generator is designed to supply constant DC voltage even with variable engine speed (14 krpm to $18 \mathrm{krpm}$ ) and electrical loads. Besides, DC voltage is designed to satisfy aircraft standards (refer to MIL-STD-704F [23]) in order to ensure compatibility between the aircraft electrical power system and other loads.

\section{Model Refefence AdAPTIVE System}

As illustrated in Fig. 7 [24], the MRAS estimator in this paper uses two models to calculate stator current of the machine. One model is a reference model and the other is an adaptive model. The error between the outputs from these two models are used to drive a suitable adaptation mechanism which generates the estimated rotor speed.

To simplify analysis, stator voltage equation (13) is converted to stator current equation:

$$
\frac{d}{d t}\left[\begin{array}{l}
i_{d 1} \\
i_{q 1} \\
i_{d 2} \\
i_{q 2}
\end{array}\right]=A\left[\begin{array}{l}
i_{d 1} \\
i_{q 1} \\
i_{d 2} \\
i_{q 2}
\end{array}\right]+B\left[\begin{array}{c}
u_{d 1} \\
u_{q 1}-\omega_{e} \varphi_{m} \\
u_{d 2} \\
u_{q 2}-\omega_{e} \varphi_{m}
\end{array}\right]
$$

where $A$ and $B$ are state matrixes that are detailed in Appendix A.

(31) can be regulated as:

$\frac{d}{d t}\left[\begin{array}{c}i_{d 1}+\frac{\varphi_{m}}{L_{d}+L_{d d}} \\ i_{q 1} \\ i_{d 2}+\frac{\varphi_{m}}{L_{d}+L_{d d}} \\ i_{q 2}\end{array}\right]=A\left[\begin{array}{c}i_{d 1}+\frac{\varphi_{m}}{L_{d}+L_{d d}} \\ i_{q 1} \\ i_{d 2}+\frac{\varphi_{m}}{L_{d}+L_{d d}} \\ i_{q 2}\end{array}\right]+B\left[\begin{array}{c}u_{d 1}+\frac{R \varphi_{m}}{L_{d}+L_{d d}} \\ u_{q 1} \\ u_{d 2}+\frac{R \varphi_{m}}{L_{d}+L_{d d}} \\ u_{q 2}\end{array}\right]$

Define

$$
\left\{\begin{array} { c } 
{ i _ { d 1 } ^ { \prime } = i _ { d 1 } + \frac { \varphi _ { m } } { L _ { d } + L _ { d d } } } \\
{ i _ { q 1 } ^ { \prime } = i _ { q 1 } } \\
{ u _ { d 1 } ^ { \prime } = u _ { d 1 } + \frac { R \varphi _ { m } } { L _ { d } + L _ { d d } } } \\
{ u _ { q 1 } ^ { \prime } = u _ { q 1 } }
\end{array} \left\{\begin{array}{c}
i_{d 2}^{\prime}=i_{d 2}+\frac{\varphi_{m}}{L_{d}+L_{d d}} \\
i_{q 2}^{\prime}=i_{q 2} \\
u_{d 2}^{\prime}=u_{d 2}+\frac{R \varphi_{m}}{L_{d}+L_{d d}} \\
u_{q 2}^{\prime}=u_{q 2}
\end{array}\right.\right.
$$

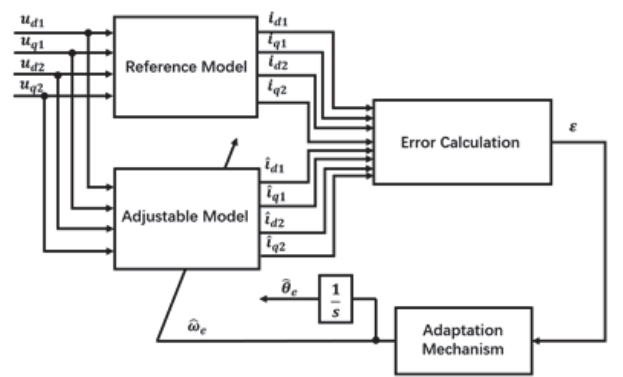

Fig. 7 Block diagram of MRAS. 
Substitute (33) into (32) giving:

$$
\frac{d}{d t}\left[\begin{array}{l}
i_{d 1}^{\prime} \\
i_{q 1}^{\prime} \\
i_{d 2}^{\prime} \\
i_{q 2}^{\prime}
\end{array}\right]=A\left[\begin{array}{l}
i_{d 1}^{\prime} \\
i_{q 1}^{\prime} \\
i_{d 2}^{\prime} \\
i_{q 2}^{\prime}
\end{array}\right]+B\left[\begin{array}{l}
u_{d 1}^{\prime} \\
u_{q 1}^{\prime} \\
u_{d 2}^{\prime} \\
u_{q 2}^{\prime}
\end{array}\right]
$$

(34) can be simplified as

$$
\frac{d}{d t} i^{\prime}=A i^{\prime}+B u^{\prime}
$$

where $i^{\prime}=\left[\begin{array}{l}i_{d 1}^{\prime} \\ i_{q 1}^{\prime} \\ i_{d 2}^{\prime} \\ i_{q 2}^{\prime}\end{array}\right], u^{\prime}=\left[\begin{array}{l}u_{d 1}^{\prime} \\ u_{q 1}^{\prime} \\ u_{d 2}^{\prime} \\ u_{q 2}^{\prime}\end{array}\right]$.

(35) is called Reference Model in Fig. 7.

The Adjustable Model in Fig. 7 is obtained by replacing actual variables in (35) with estimated variables:

$$
\frac{d}{d t} \hat{\imath}^{\prime}=\hat{A} \hat{\imath}^{\prime}+B u^{\prime}
$$

where

$$
\hat{\imath}^{\prime}=\left[\begin{array}{c}
\hat{\imath}_{d 1}^{\prime} \\
\hat{\imath}_{q 1}^{\prime} \\
\hat{\imath}_{d 2}^{\prime} \\
\hat{\imath}_{q 2}^{\prime}
\end{array}\right]=\left[\begin{array}{c}
\hat{\imath}_{d 1}+\frac{\varphi_{m}}{L_{d}+L_{d d}} \\
\hat{\imath}_{q 1} \\
\hat{\imath}_{d 2}+\frac{\varphi_{m}}{L_{d}+L_{d d}} \\
\hat{\imath}_{q 2}
\end{array}\right]
$$

$\hat{A}$ is described in Appendix A.

Define current error as

$$
e=i^{\prime}-\hat{\imath}^{\prime}=\left[\begin{array}{l}
i_{d 1}^{\prime}-\hat{\imath}_{d 1}^{\prime} \\
i_{q 1}^{\prime}-\hat{\imath}_{q 1}^{\prime} \\
i_{d 2}^{\prime}-\hat{\imath}_{d 2}^{\prime} \\
i_{q 2}^{\prime}-\hat{\imath}_{q 2}^{\prime}
\end{array}\right]
$$

Subtract (36) from (35), giving

$$
\frac{d}{d t} e=A e-(\hat{A}-A) \hat{\imath}
$$

Let

$$
W=(\hat{A}-A) \hat{\imath}
$$

Substitute $A$ and $\hat{A}$ into (40), giving

$$
W=\left(\widehat{\omega}_{e}-\omega_{e}\right) Y\left[\begin{array}{c}
\hat{\imath}_{d 1}^{\prime} \\
\hat{\imath}_{q 1}^{\prime} \\
\hat{\imath}_{d 2}^{\prime} \\
\hat{\imath}_{q 2}^{\prime}
\end{array}\right]
$$

where
$Y=\left[\begin{array}{cccc}0 & \frac{L_{d} L_{q}-L_{d d} L_{q q}}{L_{d}{ }^{2}-L_{d d}{ }^{2}} & 0 & \frac{L_{d} L_{q q}-L_{d d} L_{q}}{L_{d}{ }^{2}-L_{d d}{ }^{2}} \\ \frac{L_{d d} L_{q q}-L_{d} L_{q}}{L_{q}{ }^{2}-L_{q q}{ }^{2}} & 0 & \frac{L_{d} L_{q q}-L_{d d} L_{q}}{L_{q}{ }^{2}-L_{q q}{ }^{2}} & 0 \\ 0 & \frac{L_{d} L_{q q}-L_{d d} L_{q}}{L_{d}{ }^{2}-L_{d d}{ }^{2}} & 0 & \frac{L_{d} L_{q}-L_{d d} L_{q q}}{L_{d}{ }^{2}-L_{d d}{ }^{2}} \\ \frac{L_{d} L_{q q}-L_{d d} L_{q}}{L_{q}{ }^{2}-L_{q q}{ }^{2}} & 0 & \frac{L_{d d} L_{q q}-L_{d} L_{q}}{L_{q}{ }^{2}-L_{q q}{ }^{2}} & 0\end{array}\right]$

According to Popov's super stability theorem [25], the system is stable if the following two conditions are met [26]:

1. Transform matrix $H(s)=(s I-A)^{-1}$ is strictly positive real matrix;

2. The nonlinear time-varying link satisfies the Popov integral inequality, that is $\eta\left(0, t_{0}\right)=\int_{0}^{t_{0}} e^{T} W d t \geq-\gamma_{0}^{2}$, $\forall t_{0} \geq 0, \gamma_{0}^{2}$ can be any finite positive number

Solve the Popov integral inequality inversely, giving

$$
\widehat{\omega}_{e}=\left(K_{p}+\frac{K_{i}}{s}\right) \varepsilon
$$

where $\varepsilon$ is the output of Error Calculation in Fig. 7 that is defined as:

$$
\varepsilon=i_{d 1}^{\prime} \hat{\imath}_{q 1}^{\prime}-\hat{\imath}_{d 1}^{\prime} i_{q 1}^{\prime}+i_{d 2}^{\prime} \hat{l}_{q 2}^{\prime}-\hat{\imath}_{d 2}^{\prime} i_{q 2}^{\prime}
$$

$K_{p}$ and $K_{i}$ are parameters of a PI controller which is designed as the Adaptation Mechanism in Fig. 7.

Substitute (33) and (37) into (43) and then substitute (43) into (42) giving:

$$
\begin{gathered}
\widehat{\omega}_{e}=\left(K_{p}+\frac{K_{i}}{s}\right)\left[i_{d 1} \hat{\imath}_{q 1}-\hat{\imath}_{d 1} i_{q 1}+i_{d 2} \hat{\imath}_{q 2}-\hat{\imath}_{d 2} i_{q 2}-\right. \\
\left.\frac{\varphi_{m}}{L_{d}}\left(i_{q 1}-\hat{\imath}_{q 1}+i_{q 2}-\hat{\imath}_{q 2}\right)\right]
\end{gathered}
$$

As shown in Fig. 7, the estimated position angle of the rotor can be got by integral of estimated speed:

$$
\hat{\theta}_{e}=\int \widehat{\omega}_{e} d \tau
$$

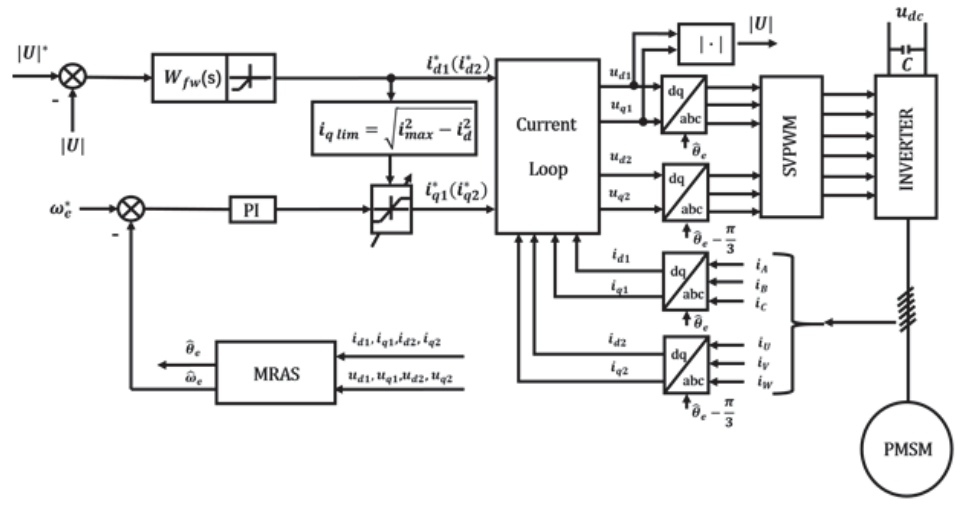

Fig. 8 Block diagram of sensorless system in starter mode. 


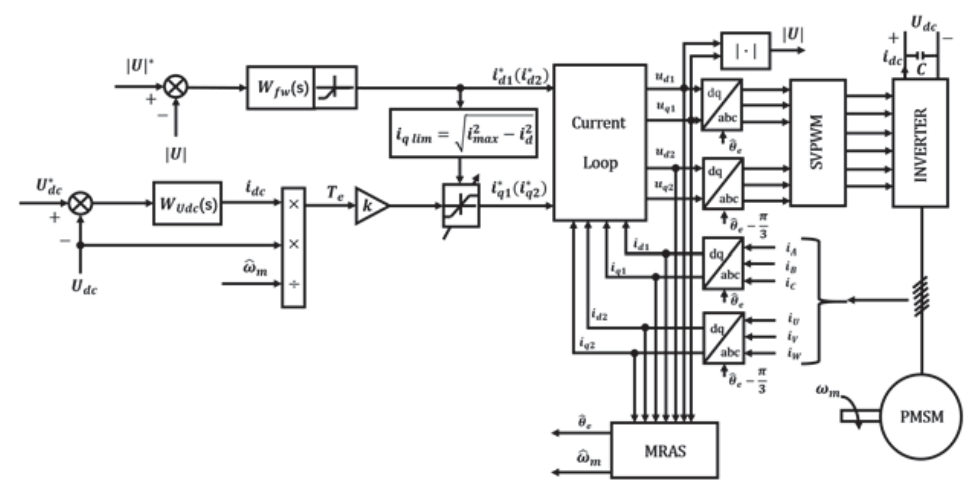

Fig. 9 Block diagram of sensorless system in generator mode.

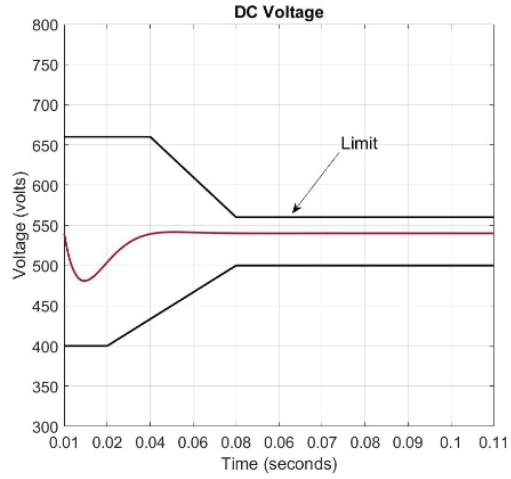

Fig. 10 Simulation results of DC voltage in generator mode.

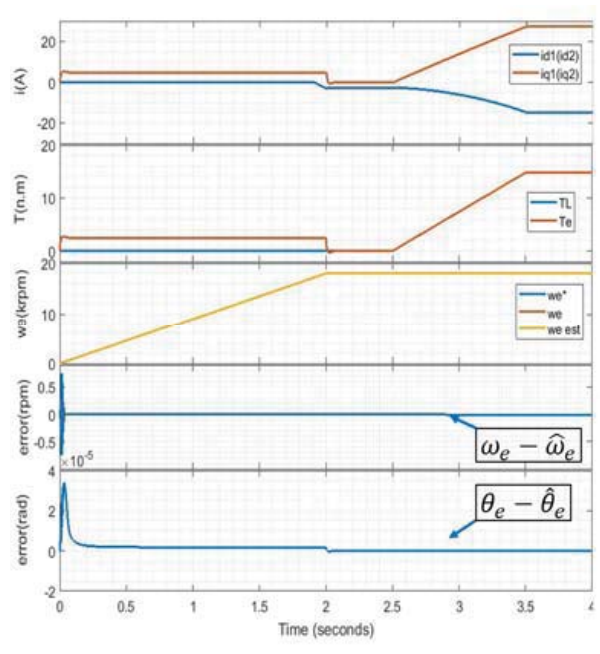

(a)

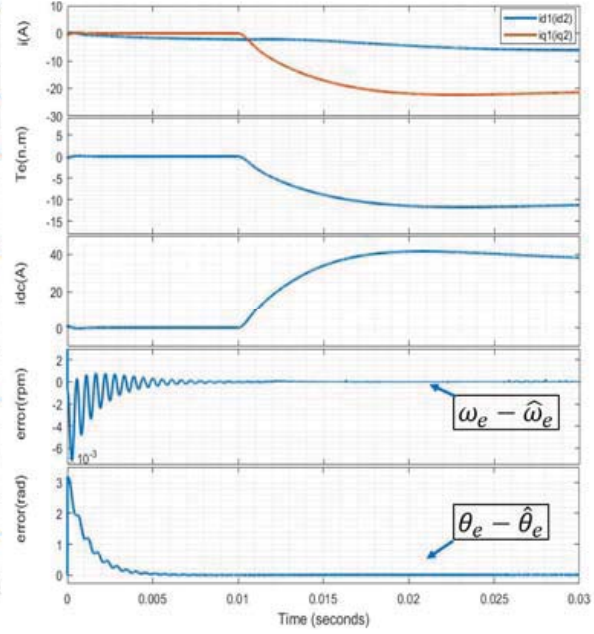

(b)

Fig. 11 Simulation results of system (a) starter mode (b) generator mode.
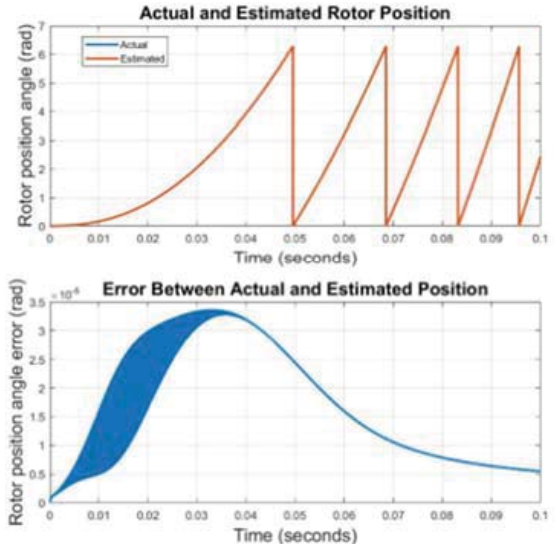

(a)
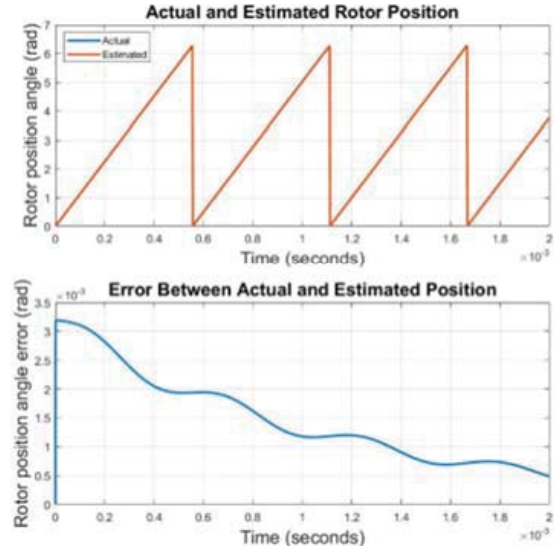

(b)

Fig. 12 Comparison of actual and estimated rotor position (a) starter mode (b) generator mode.

\section{Simulation Results}

Performance of designed sensorless $\mathrm{S} / \mathrm{G}$ system has been verified through time-domain simulation using system models (Fig. 8 and Fig. 9) build in MATLAB/SimPower. Simulations of starter mode operation are given in Fig. 11(a) and Fig. 12(a). In starter mode, there are two stages. The first stage covers from beginning to $2.5 \mathrm{~s}$ while the second stage lasts from $2.5 \mathrm{~s}$ to $4 \mathrm{~s}$. In the first stage, there is no load torque and rotor speed increases steadily from $0 \mathrm{rpm}$ to $18 \mathrm{krpm}$ during the first two seconds and retains at $18 \mathrm{krpm}$ afterwards. 
Based on speed response characteristic, the response of electromagnetic torque can be verified by applying parameters in Table. 1 to (14). By plotting $d q$ axis current responses in the voltage and current limit circle, the current trajectory during this period moves along the green locus from point $\mathrm{O}$ to point $\mathrm{A}$ and then point $\mathrm{B}$ as shown in Fig. 5 . In the second stage, a torque load is applied which grows steadily from 0 N.m to $100 \%$ rated load -14.8 N.m between $2.5 \mathrm{~s}$ and $3.5 \mathrm{~s}$ and keeps constant to the end of simulation. It can be observed immediately that electromagnetic torque and voltages in $d q$ frame have good responses. The current trajectory during this interval moves along the voltage limit ellipse of $18 \mathrm{krpm}$ as the green locus from point B to point C in Fig. 5. In both stages, the current trajectory of starter mode is always within current limit circle, which is an identification of system capabilities and limitations discussed in section III. Besides, in both stages, the $d q$ frame voltage response figure, $u_{d_{1,2}}, u_{q_{1,2}}$ and their square root $|\mathrm{u}|$ are always within voltage limit range $\left[-U_{\max },+U_{\max }\right]$. Hence, good flux weakening control performance is confirmed. In Fig. 12 (a), the estimated rotor position is compared with the actual position. The maximum position error between them is less than $3.5 \times 10^{-5} \mathrm{rad}$, indicating the satisfactory robustness of this estimation method.

Results of generator mode are shown in Fig. 11(b) and Fig. 12(b). In generator mode, there are also two stages. The first stage lasts from beginning to $0.01 \mathrm{~s}$ and then the second stage starts until the end of simulation. In the first stage, the power system is not subjected to any load. The current trajectory of this stage is the red straight line from point $\mathrm{O}$ to point B shown in Fig. 5. At the beginning of second stage, a full load $(20 \mathrm{KW})$ is applied to the system in the form of a step function. The electromagnetic torque in steady state is observed as -10.9 N.m in Fig. 11(b). Since the rotor speed is a constant value $(18 \mathrm{krpm})$, the value of electromagnetic torque can be verified by (20). The current trajectory of this stage moves along the voltage limit ellipse of $18 \mathrm{krpm}$ from point $\mathrm{B}$ to point $\mathrm{D}$ as depicted in Fig. 5. The negative sign of both electromagnetic torque and $q$-axis current confirm that the machine operates as a generator. As observed in Fig. 10, $\mathrm{DC}$ voltage response is within limitation boundaries. Hence, the effectiveness of DC voltage control can be verified. In Fig. 12(b), the estimated rotor position is compared with the actual position. The maximum position error between them is larger than that of starter mode but still tiny, less than $3.5 \times 10^{-3} \mathrm{rad}$, which proves good performance of estimator.

\section{CONCLUSIONS}

A robust speed estimator based on an MRAS structure has been proposed for a sensorless symmetric DTP-PMSM. The proposed MRAS approach can be applied both in starter mode and generator mode for MEA. It has been shown that the rotor speed and position can be accurately tracked in both modes. The robustness of the proposed system is confirmed in the case of load torque variation and the effectiveness of the proposed algorithm is verified by simulation results.

\section{ACKNOWLEDGEMENT}

This project has received funding from the Clean Sky 2 Joint Undertaking under the European Union's Horizon 2020 research and innovation program under grant agreement No 737814 .

\section{REFERENCE}

[1] Bose, B.K., Global energy scenario and impact of power electronics in 21st century. IEEE Transactions on Industrial Electronics, 2013. 60(7): p. 2638-2651

[2] Moir, I. and A. Seabridge, Aircraft systems: mechanical, electrical and avionics subsystems integration. Vol. 52. 2011: John Wiley \& Sons.

[3] Levi, E., Multiphase electric machines for variable-speed applications. IEEE Transactions on industrial electronics, 2008. 55(5): p. 1893-1909.

[4] Karttunen, J., et al. Dual three-phase permanent magnet synchronous machine supplied by two independent voltage source inverters. in Power Electronics, Electrical Drives, Automation and Motion (SPEEDAM), 2012 International Symposium on. 2012. IEEE.

[5] Bojoi, R., et al., Digital field-oriented control for dual three-phase induction motor drives. IEEE Transactions on Industry Applications, 2003. 39(3): p. 752-760.

[6] Singh, G.K., K. Nam, and S. Lim, A simple indirect field-oriented control scheme for multiphase induction machine. IEEE Transactions on Industrial Electronics, 2005. 52(4): p. 1177-1184.

[7] Bojoi, R., et al., Vector control of dual-three-phase induction-motor drives using two current sensors. IEEE Transactions on Industry Applications, 2006. 42(5): p. 1284-1292.

[8] Scelba, G., et al. Compensation of rotor positon estimation errors in sensorless dual-three phase PMSM drives through back-EMF sensing. in Sensorless Control for Electrical Drives (SLED), 2017 IEEE International Symposium on. 2017. IEEE.

[9] Bojoi, R., et al. Multiphase PM machine for more electric aircraft applications: Prototype for design validation. in IECON 2012-38th Annual Conference on IEEE Industrial Electronics Society. 2012. IEEE.

10] $\mathrm{Xu}, \mathrm{P}$. and $\mathrm{Z}$. Zhu, Initial rotor position estimation using zerosequence carrier voltage for permanent-magnet synchronous machines. IEEE Transactions on Industrial Electronics, 2017. 64(1): $\mathrm{p}$ 149-158.

[11] Rashed, M., et al., Sensorless indirect-rotor-field-orientation speed control of a permanent-magnet synchronous motor with statorresistance estimation. IEEE transactions on industrial electronics, 2007. 54(3): p. 1664-1675.

[12] Kumar, R., et al., Review on model reference adaptive system for sensorless vector control of induction motor drives. IET Electric Power Applications, 2015. 9(7): p. 496-511.

[13] Raca, D., et al., Carrier-signal selection for sensorless control of PM synchronous machines at zero and very low speeds. IEEE Transactions on Industry Applications, 2010. 46(1): p. 167-178.

[14] Consoli, A., G. Scarcella, and A. Testa, Industry application of zerospeed sensorless control techniques for PM synchronous motors. IEEE Transactions on Industry Applications, 2001. 37(2): p. 513-521.

[15] Gopakumar, K., V. Ranganathan, and S. Bhat, Split phase induction motor operation from PWM voltage source inverter. 1991.

[16] Skvarenina, T.L., The power electronics handbook. 2001: CRC press.

[17] Hu, Y., Z. Zhu, and M. Odavic, Comparison of two-individual current control and vector space decomposition control for dual three-phase PMSM. IEEE Transactions on Industry Applications, 2017. 53(5): p. 4483-4492.

[18] Bozhko, S., et al. Aircraft starter-generator system based on permanent-magnet machine fed by active front-end rectifier. in Industrial Electronics Society, IECON 2014-40th Annual Conference of the IEEE. 2014. IEEE.

[19] Bozhko, S., et al. Aircraft starter-generator system based on permanent-magnet machine fed by active front-end rectifier. in IECON 2014 - 40th Annual Conference of the IEEE Industrial Electronics Society. 2014.

[20] Suvo, Electrical Power vs Mechanical Power. 2010, BRIGHT HUB ENGINEERING.

[21] Leonhard, W., Adjustable-speech AC drives. Proceedings of the IEEE, 1988. 76(4): p. 455-471.

[22] Yeoh, S.S., Control strategies for the More Electric Aircraft startergenerator electrical power system. 2016, University of Nottingham. 
[23] MIL-STD-704F Aircraft Electric Power Characteristics. 2004, Department of Defense Interface Standard, United States of America.

[24] Y. Xing, X.W., D. Yang and Z. M. Zhang, Sensorless Control of Permanent Magnet Synchronous Motor Based on Model Reference Adaptive System, in 2017 10th International Symposium on Computational Intelligence and Design (ISCID). 2017: Hangzhou.

[25] S.Wu, Z., Principle and application of adaptive control. 2005, Harbin: Harbin Institute of Technology press,.

[26] Xu, J., et al. Research on speed sensorless operation of PMSM based on improved MRAS. in Control Conference (ASCC), 2017 11th Asian. 2017. IEEE.

\section{APPENDIX A}

$\boldsymbol{M}_{\boldsymbol{o}}$ and $\boldsymbol{M}_{\boldsymbol{x}}$ are matrixs in inductance equation (3):

$$
\boldsymbol{M}_{\boldsymbol{o}}=\left[\begin{array}{cccccc}
1 & -\frac{1}{2} & -\frac{1}{2} & \frac{1}{2} & -1 & \frac{1}{2} \\
-\frac{1}{2} & 1 & -\frac{1}{2} & \frac{1}{2} & \frac{1}{2} & -1 \\
-\frac{1}{2} & -\frac{1}{2} & 1 & -1 & \frac{1}{2} & \frac{1}{2} \\
\frac{1}{2} & \frac{1}{2} & -1 & 1 & -\frac{1}{2} & -\frac{1}{2} \\
-1 & \frac{1}{2} & \frac{1}{2} & -\frac{1}{2} & 1 & -\frac{1}{2} \\
\frac{1}{2} & -1 & \frac{1}{2} & -\frac{1}{2} & -\frac{1}{2} & 1
\end{array}\right]
$$$$
B=\left[\begin{array}{cccc}
\frac{L_{d}}{L_{d}{ }^{2}-L_{d d^{2}}} & 0 & -\frac{L_{d d}}{L_{d}{ }^{2}-L_{d d^{2}}} & 0 \\
0 & \frac{L_{q}}{L_{q^{2}-L_{q q^{2}}}} & 0 & -\frac{L_{q q}}{L_{q^{2}-L_{q q^{2}}}} \\
-\frac{L_{d d}}{L_{d}{ }^{2}-L_{d d^{2}}} & 0 & \frac{L_{d}}{L_{d}{ }^{2}-L_{d d^{2}}} & 0 \\
0 & -\frac{L_{q q}}{L_{q^{2}}{ }^{2} L_{q q^{2}}} & 0 & \frac{L_{q}}{L_{q^{2}-L_{q q^{2}}}}
\end{array}\right]
$$

$$
A=
$$

$$
\begin{gathered}
A= \\
-\frac{L_{d} R}{L_{d}^{2}-L_{d d}{ }^{2}} \\
\frac{\omega_{e}\left(L_{\left.d d^{2} L_{q q}-L_{d} L_{q}\right)}\right.}{L_{q^{2}-L_{q q^{2}}}} \\
\frac{L_{d d} R}{L_{d}{ }^{2}-L_{d d^{2}}{ }^{2}} \\
\frac{\omega_{e}\left(L_{d} L_{q q}-L_{d d^{2}} L_{q}\right)}{L_{q}{ }^{2}-L_{q q^{2}}{ }^{2}}
\end{gathered}
$$

$\hat{A}=$

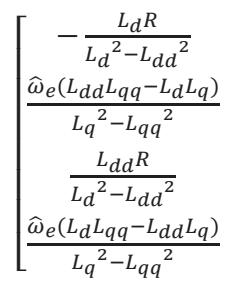

$\frac{\omega_{e}\left(L_{d} L_{q}-L_{d d} L_{q q}\right)}{L_{d}^{2}-L_{d d^{2}}}$

$$
-\frac{L_{q} R}{L_{q}{ }^{2}-L_{q q^{2}}}
$$$$
L_{d}{ }^{2}-L_{d d}
$$

$\frac{\omega_{e}\left(L_{d} L_{q q}-L_{d d} L_{q}\right)}{L_{d}{ }^{2} L_{d d}}$

$$
L_{d}{ }^{2}-L_{d d}
$$$$
\frac{L_{q q} R}{L_{q}{ }^{2}-L_{q q}}
$$

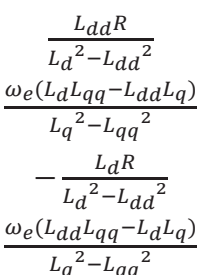

$\frac{\omega_{e}\left(L_{d} L_{q q}-L_{d d} L_{q}\right)}{L_{d}-L_{d d^{2}}}$

$L_{d}{ }^{2}-L_{d d}{ }^{2}$ $\frac{L_{q q} R}{L_{q}{ }^{2}-L_{q q}{ }^{2}}$ $\omega_{e}\left(L_{d} L_{q}-L_{d d} L_{q q}\right)$ $L_{d}^{2}-L_{d d}{ }^{2}$ $-\frac{L_{q} R}{L_{q}{ }^{2}-L_{q q}{ }^{2}}$

$\frac{\widehat{\omega}_{e}\left(L_{d} L_{q}-L_{d d} L_{q q}\right)}{2}$

$\frac{L_{d d} R}{L_{d}^{2}-L_{d d}{ }^{2}}$ $\widehat{\omega}_{e}\left(L_{d} L_{q q}-L_{d d} L_{q}\right)$ $\frac{\widehat{\omega}_{e}\left(L_{d} L_{q q}-L_{d d} L_{q}\right)}{L_{d}-L_{d d}}$ $L_{d}{ }^{2}-L_{d d}$ $-\frac{L_{d} R}{L_{d}{ }^{2}-L_{d d}{ }^{2}}$ $\frac{\widehat{\omega}_{e}\left(L_{d d} L_{q q}-L_{d} L_{q}\right)}{L_{q}{ }^{2}-L_{q q}{ }^{2}}$ $L_{d}{ }^{2}-L_{d d^{2}}$
$\frac{L_{q q} R}{L_{q}{ }^{2}-L_{q q^{2}}}$
$\frac{\widehat{\omega}_{e}\left(L_{d} L_{q}-L_{\left.d d^{2} L_{q q}\right)}\right.}{L_{d}{ }^{2}-L_{d d^{2}}}$
$-\frac{L_{q} R}{L_{q}{ }^{2}-L_{q q^{2}}{ }^{2}}$

$A, \hat{A}$ and $B$ are matrixs in current equation (35) and (36):

$$
\boldsymbol{M}_{\boldsymbol{x}}=\left[\begin{array}{cccccc}
\cos 2 \theta & \cos \left(2 \theta-\frac{2 \pi}{3}\right) & \cos \left(2 \theta+\frac{2 \pi}{3}\right) & \cos \left(2 \theta-\frac{\pi}{3}\right) & \cos (2 \theta-\pi) & \cos \left(2 \theta+\frac{\pi}{3}\right) \\
\cos \left(2 \theta-\frac{2 \pi}{3}\right) & \cos \left(2 \theta+\frac{2 \pi}{3}\right) & \cos 2 \theta & \cos (2 \theta-\pi) & \cos \left(2 \theta+\frac{\pi}{3}\right) & \cos \left(2 \theta-\frac{\pi}{3}\right) \\
\cos \left(2 \theta+\frac{2 \pi}{3}\right) & \cos 2 \theta & \cos \left(2 \theta-\frac{2 \pi}{3}\right) & \cos \left(2 \theta+\frac{\pi}{3}\right) & \cos \left(2 \theta-\frac{\pi}{3}\right) & \cos (2 \theta-\pi) \\
\cos \left(2 \theta-\frac{\pi}{3}\right) & \cos (2 \theta-\pi) & \cos \left(2 \theta+\frac{\pi}{3}\right) & \cos \left(2 \theta-\frac{2 \pi}{3}\right) & \cos \left(2 \theta-\frac{4 \pi}{3}\right) & \cos 2 \theta \\
\cos (2 \theta-\pi) & \cos \left(2 \theta+\frac{\pi}{3}\right) & \cos \left(2 \theta-\frac{\pi}{3}\right) & \cos \left(2 \theta-\frac{4 \pi}{3}\right) & \cos 2 \theta & \cos \left(2 \theta-\frac{2 \pi}{3}\right) \\
\cos \left(2 \theta+\frac{\pi}{3}\right) & \cos \left(2 \theta-\frac{\pi}{3}\right) & \cos (2 \theta-\pi) & \cos 2 \theta & \cos \left(2 \theta-\frac{2 \pi}{3}\right) & \cos \left(2 \theta-\frac{4 \pi}{3}\right)
\end{array}\right]
$$

APPENDIX B

Table 1 Parameters of machine

\begin{tabular}{cccc}
\hline \hline Parameter & Mark & Value & Unit \\
\hline Phase Resistance & $R$ & 0.41 & Ohm \\
\hline D-axis Inductance & $L_{d}$ & 365 & $\mu \mathrm{H}$ \\
\hline Q-axis Inductance & $L_{q}$ & 410 & $\mu \mathrm{H}$ \\
\hline Leakage Inductance & $L_{z}$ & 291 & $\mu \mathrm{H}$ \\
\hline Rotational Inertia & $J$ & 0.00263 & $\mathrm{~kg} \cdot \mathrm{m}^{2}$ \\
\hline $\begin{array}{c}\text { Peak No-load Flux } \\
\text { Linkage per Channel }\end{array}$ & $\varphi_{m}$ & 0.0287 & $\mathrm{~V} \cdot \mathrm{s}$ \\
\hline Pole Pairs number & $P_{P}$ & 6 & \\
\hline Phase Peak Current & $I_{\max }$ & 34 & $\mathrm{~A}$ \\
\hline Phase Peak Voltage & $U_{\max }$ & 311 & $\mathrm{~V}$ \\
\hline Base Speed/Max \\
Speed
\end{tabular}

